\title{
Clinical evaluation of glucagon by continuous infusion in the treatment of low cardiac output states
}

\author{
Condon R. Vander Ark, M.D. \\ Ernest W. Reynolds, Jr., M.D., F.A.C.C. \\ Ann Arbor, Mich.
}

\begin{abstract}
Qtudy of the cardiovascular effects of 0 glucagon in man have shown a positive inotropic and chronotropic effect resulting in an increase in cardiac output. ${ }^{2-3}$ These effects occur one to 3 minutes after the intravenous injection of 3 to $5 \mathrm{mg}$. of glucagon and are dissipated in $\mathbf{3 0}$ minutes. These effects are similar to those of isoproterenol; however, glucagon has a limited chronotropic effect in $\operatorname{man}^{1}$ and has not caused arrhythmias even in the presence of digitalis. ${ }^{2}$ In contrast, a recent study of patients with chronic valvular heart disease concluded that these cardiac effects were variable, not dose-related, and of small magnitude when present. ${ }^{4}$ In addition to these cardiac effects, glucagon has been shown to increase renal excretion of water and electrolytes. ${ }^{5}$ Since previous studies are limited to the observation of the effects of a single bolus injection, given to patients who were not in stress situations, it seemed appropriate to study the feasibility and efficacy of a continuous infusion of glucagon over a period of days in the treatment of conditions with low cardiac output or cardiogenic shock.
\end{abstract}

\section{Methods}

Lyophilized glucagon (Eli Lilly \& Co.) was mixed with diluent and a small volume of 5 per cent glucose and water and placed in an in-line burette with an administration set adapter* to carefully control fluid volume and glucagon dosage. Since solutions of glucagon deteriorate at room temperature, these solutions were prepared fresh every hour. When potassium supplement was required, $20 \mathrm{mEq}$. of $\mathrm{KCl}$ was given orally or added to the intravenous fluids. Standard clinical techniques were used to record blood pressure and fluid balance. Blood glucose, serum $\mathrm{Na}^{+}$, $\mathrm{K}^{+}, \mathrm{Cl}^{-}, \mathrm{HCO}_{3}^{-}, \mathrm{Ca}^{++}$, creatinine, and blood urea nitrogen were determined with standard techniques in the clinical pathology laboratories.

Table I lists the basic cardiac diagnosis and the clinical state of each patient at the time glucagon infusion was started as well as their response to therapy. Sixteen patients received 18 glucagon infusions at an average rate of $4.0 \mathrm{mg}$. per hour (1 to 16 mig. per hour) for an average treatment period of 4.9 days ( 0.1 to 12 days). All

From the Heart Station, Department of Internal Medicine, University of Michigan Medical Center. Ann Arbor, Mich.

This study was supported in part by the Michigan Heart Association.

Received for publication July 7, 1969.

Reprint requests to: Dr. Vander Ark, Department of Internal Medicine, Heart Station, University Hospital, University of Michigan Medical Center, Ann Arbor, Mich. 48104.

*Baxter Laboratories: Plexitron Buretrol R67M and set adapter R 38 M50. 


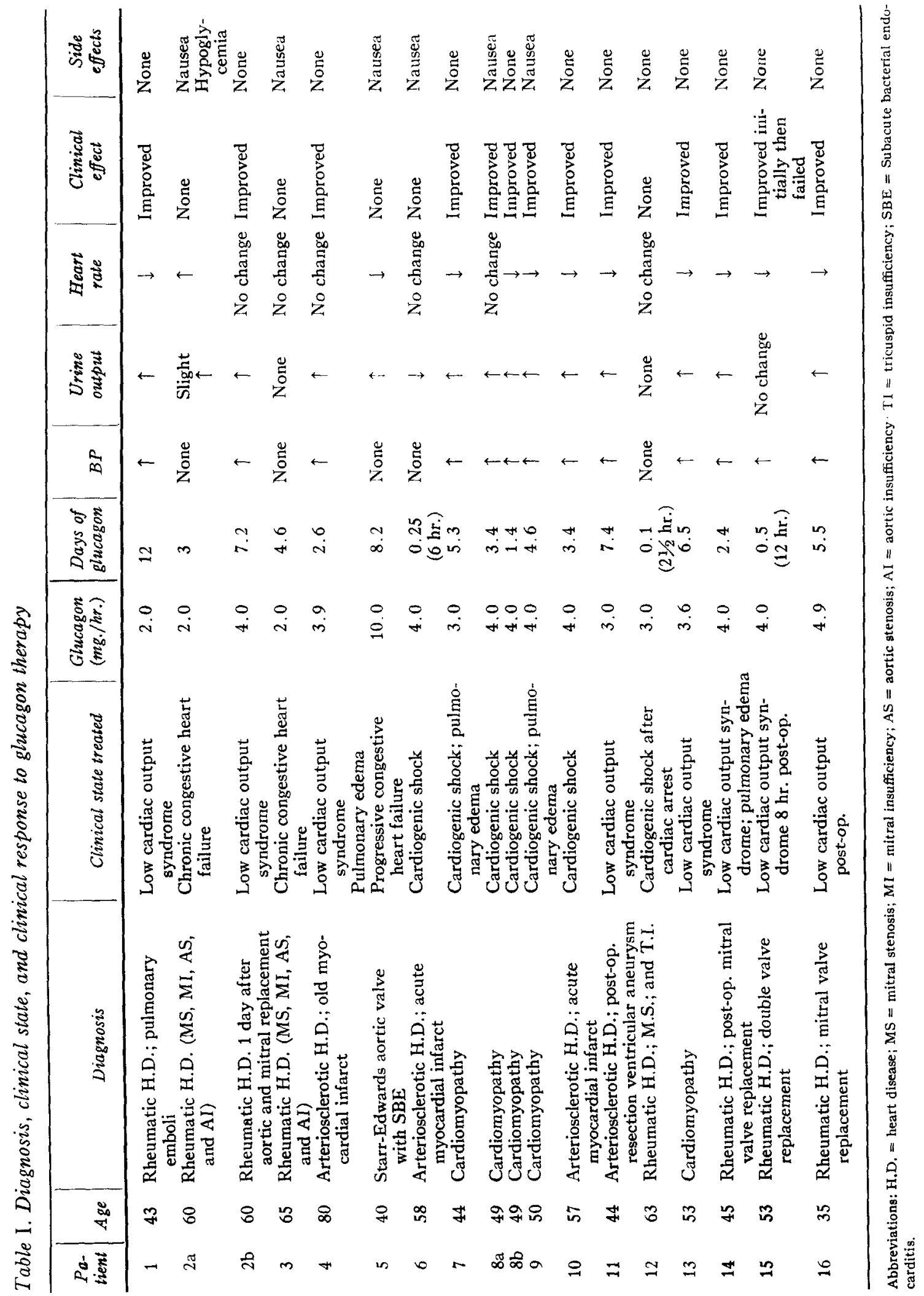


patients were receiving digitalis. Only 2 of the 16 patients received diuretic agents during the first 24 hours of glucagon infusion. Cases 4 and 5 were on maintenance diuretics before and during the glucagon infusion and the dosage was not changed. Nine patients received diuretics later in the course of glucagon therapy to effect further diuresis during glucagon support of cardiac function.

\section{Results}

Blood pressure (Fig. 1). Five patients had no obtainable blood pressure at the time glucagon was started and 9 additional patients had systolic pressures of $90 \mathrm{~mm}$. $\mathrm{Hg}$ or lower. Twelve of these 14 patients responded to glucagon with an increase in blood pressure. Two patients (Nos. 6 and 12) were in irreversible shock, unresponsive to vasopressors, for 14 and 12 hours, respectively, before glucagon was started and died 6 and $2 \frac{1}{2}$ hours, respectively, after starting glucagon with no change in any parameter. One patient had severe hypotension reversed with isoproterenol infusion, but because of tachycardia (140 per minute) and oliguria she was switched to glucagon with maintenance of blood pressure, an increase in urine output, and a decrease in heart rate. Two patients with normal blood pressures received glucagon therapy and there was no change in blood pressure or evidence of clinical improvement in their signs and symptoms of congestive heart failure.

The mean increase in systolic blood pressure was $34 \mathrm{~mm} . \mathrm{Hg}(\mathrm{p}<0.01)$ and the mean increase in diastolic pressure was $28 \mathrm{~mm}$. Hg $(\mathrm{p}<0.01)$. The increase in blood pressure was seen within 15 minutes in 4 patients and as late as 90 minutes in one patient.

Urine output (Fig. 2). All patients who improved clinically had an increase in urine output. The mean urine output for the 8 hours before glucagon was 149 c.c. and for the first 8 hours on glucagon was 430 c.c., an average increase of 282 c.c. $(p<0.01)$. This 16 hour period was selected since no diuretic or other therapy was given or changed during this period which could have influenced this response to glucagon.

Heart rate and thythm (Fig. 2). Six patients had atrial fibrillation as their basic rhythm, 9 had sinus tachycardia, and one had normal sinus rhythm ( 80 per minute). The mean ventricular rate before glucagon was 107 per minute. One patient had an increase in the ventricular rate from 70 to
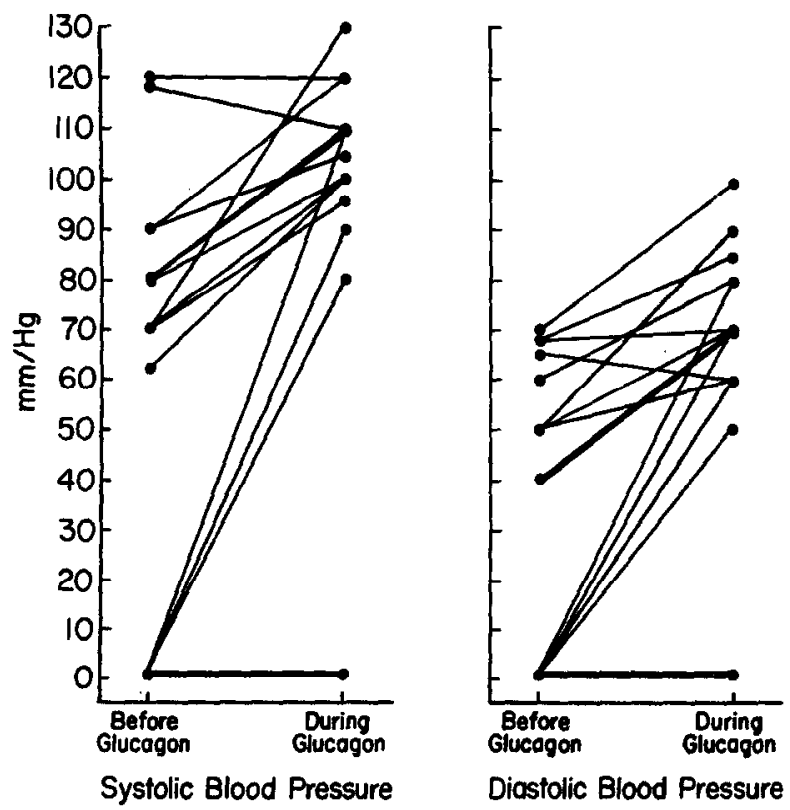

Fig. 1. Glucagon produced a significant $(\mathrm{p}<0.01)$ increase in systolic and diastolic blood pressure. 


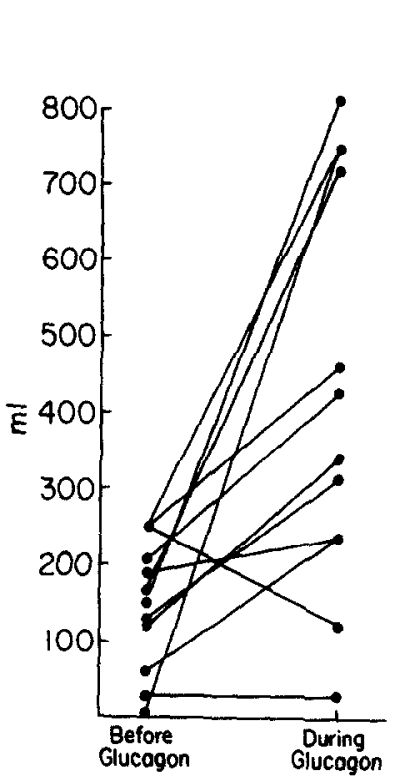

Total Eight hr. Urine Output

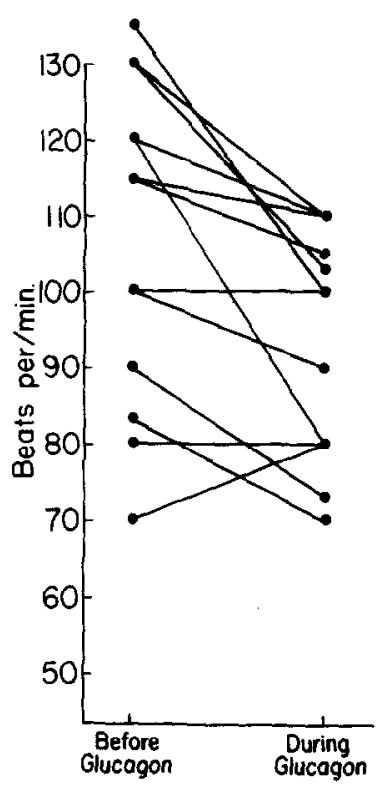

Ventricular Rate

Fig. 2. Glucagon produced a significant increase in urine output $(\mathrm{p}<0.01)$ and a decrease in ventricular rate $(\mathrm{p}<0.01)$ in patients with cardiac decompensation.

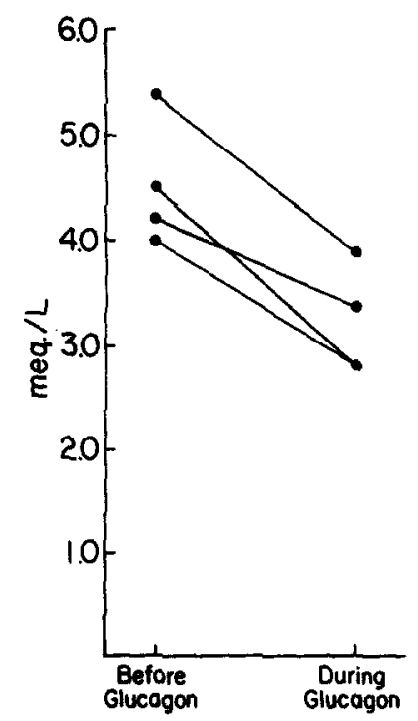

Serum $\mathrm{K}^{+}$Without Supplement

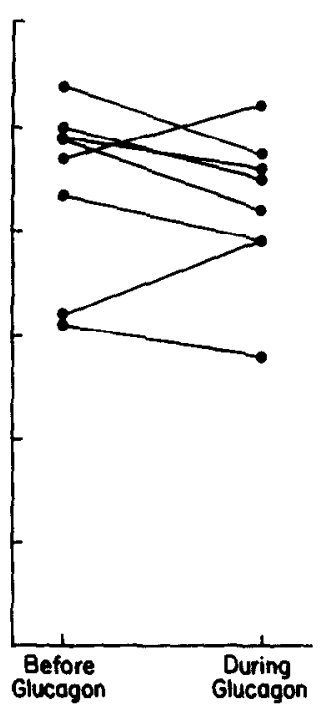

Serum $\mathrm{K}^{+}$With Supplement

Fig. 3. Glucagon produced a decrease in serum potassium which can be prevented by giving $\mathrm{KCl}$ supplements with the initial infusion. 
80 per minute, 3 patients were unchanged, and all the other patients had a decrease in ventricular rate. The mean ventricular rate during glucagon therapy was 93 per minute, a decrease of 14 per minute $(\mathrm{p}<$ 0.01 ).

Five patients had paroxysmal arrhythmias during the 24 hours before glucagon was started. One patient had paroxysmal atrial tachycardia (PAT) with block due to digitalis toxicity, one had paroxysms of atrial fibrillation, and 3 had paroxysms of ventricular tachycardia. These patients had no paroxysmal arrhythmias during glucagon therapy.

Serum electrolytes (Fig. 3). In 4 patients glucagon infusion was instituted without potassium supplements. The mean serum potassium before glucagon was $4.5 \mathrm{mEq}$. per liter and within 6 hours the mean potassium was $3.2 \mathrm{mEq}$. per liter. All of the other patients had $20 \mathrm{mEq}$. of $\mathrm{KCl}$ along with the initial infusion of glucagon, and there was no significant change in serum potassium, $4.3 \mathrm{mEq}$. per liter before glucagon and $4.2 \mathrm{mEq}$. per liter after glucagon was started. Three patients developed hy perkalemia of $7.7,6.6$, and $8.0 \mathrm{mEq}$. per liter on the third, seventh, and fifth days of glucagon infusions with $\mathrm{KCl}$ supplements which required discontinuing potassium and treatment with exchange resins. Two of these patients had failed to improve with glucagon and had deteriorating renal function with rising serum creatinines to 3.5 and $4.9 \mathrm{mg}$. per cent, respectively. The third patient was receiving $120 \mathrm{mEq}$. of $\mathrm{KCl}$ supplements daily but had normal renal function studies and good urine output, and the reason for the hyperkalemia was not clear. There was no significant change in other serum electrolytes.

Blood glucose. Fifteen patients had no known abnormality of glucose tolerance and one patient had diabetes mellitus. The mean \pm one standard deviation of all blood sugar determinations made in nondiabetic patients while receiving glucagon was $151 \pm 32 \mathrm{mg}$. per cent. None of these patients required therapy for hyperglycemia. Patient 10 was a known diabetic controlled with oral hypoglycemic agents before her acute myocardial infarction. On admission to the hospital her blood sugar was $384 \mathrm{mg}$. per cent and insulin therapy was given. On the fourth hospital day the patient developed cardiogenic shock and glucagon therapy was started and insulin continued. Myocardial infarction and glucagon would both be expected to increase the insulin requirement, and it was not possible to determine the specific effect of these two factors. No major change in insulin dosage was required.

Side effects. The major side effect was nausea in 6 of the 16 patients. Nausea necessitated stopping the drug in one patient, at his request, but was reasonably well tolerated in the other 5 . Nausea appears to be dose-related, but a specific dose level could not be determined due to individual patient variations.

The first patient to receive a continuous infusion of glucagon had a hypoglycemic reaction. The glucagon had been prepared to run over a 24 hour period. Twenty hours after this solution was started, the patient developed atrial flutter with variable $A-V$ block and a ventricular rate of 140 to 160 beats per minute. The patient became dyspneic, diaphoretic, and had no obtainable blood pressure. A blood sample was collected and she was treated with 50 c.c. of a 50 per cent glucose solution; a $2 \mathrm{mg}$. bolus of glucagon and a fresh solution of glucagon was started. She also received $0.4 \mathrm{mg}$. of lanatoside-C and $3 \mathrm{mg}$. of morphine sulfate intravenously. Laboratory data from the blood sample revealed a blood glucose of $40 \mathrm{mg}$. per cent, serum sodium of $138 \mathrm{mEq}$. per liter, potassium of $6.3 \mathrm{mEq}$. per liter, and blood urea nitrogen of $60 \mathrm{mg}$. per cent. One hour later she was comfortable with a ventricular rate of 90 per minute and a blood pressure of $94 / 70$ $\mathrm{mm}$. Hg. Two days later the patient underwent successful replacement of her mitral and aortic valves, though she did require glucagon therapy in the postoperative period. This observation suggested that glucagon deteriorates in solution at room temperature. When glucagon infusions following this episode were freshly prepared, every 4 hours, no further hypoglycemia was seen. When glucagon was discontinued, a 5 per cent glucose-in-water infusion was continued for 3 to 4 hours to prevent reactive hypoglycemia. 
Patient No. 5 received glucagon at the rate of $16 \mathrm{mg}$. per hour for 3 days and no toxic effects were seen in this patient nor in any other patients. There was no clinical evidence of tachyphylaxis.

\section{Discussion}

Glucagon is a polypeptide produced by the alpha cells of the pancreas and has been used clinically to treat hypoglycemia, ${ }^{6}$ evaluate hepatic glycogen stores, ${ }^{7}$ and as a provocative test for pheochromocytoma. ${ }^{8}$

Lucchesi $^{9}$ and Glick and associates ${ }^{10}$ have demonstrated that in the experimental animal beta-receptor blockade with propranolol does not abolish the positive inotropic effect of glucagon. This was demonstrated in our first patient who was admitted to University Hospital with a low cardiac output syndrome, PAT with block due to digitalis intoxication, and a blood pressure of $85 / 60 \mathrm{~mm}$. $\mathrm{Hg}$. Digitalis was stopped and since it was felt that the low cardiac output was secondary to the rapid rate, $30 \mathrm{mg}$. of propranolol were given orally with conversion of the rhythm to normal. The oliguria and hypotension continued, however, and after the patient had received a total of $90 \mathrm{mg}$. of propranolol over a 24 hour period, glucagon was started. Within 15 minutes after starting glucagon, the blood pressure rose from $60 / 30$ to $96 / 65$ $\mathrm{mm}$. $\mathrm{Hg}$, and over the next 8 hours urine output increased. Propranolol was then discontinued and no further arrhythmias were observed. Glucagon appears to be the drug of choice in the treatment of excessive cardiac depression due to beta-blocking agents.

Glucagon is known to increase the release of glucose from the liver and insulin from the pancreas. This results in an increase in peripheral glucose utilization and a transfer of extracellular potassium to the intracellular compartment with a resultant decrease in serum potassium. This effect was clearly demonstrated in the 4 patients who received glucagon without initial potassium supplements. This is of major concern in patients of the type studied here, all of whom were on digitalis and subject to the potential risk of arrhythmias should significant hypokalemia develop. As demonstrated this hazard can be handled by starting potassium supplements with the glucagon; however, frequent serum potassium determinations are essential in following these patients since most (11 of 16) in this series have impaired renal function with elevated serum creatinines.

Glucagon has a positive chronotropic effect ${ }^{11}$ though this is not as marked as that seen with isoproterenol. This effect was not seen in this series of patients since most of them had severe cardiac decompensation and resultant tachycardias. When cardiac function was inproved, apparently due to the inotropic effect of glucagon infusion, the heart rate decreased. This may be due to a decrease in sympathetic tone and decreased release of endogenous catecholamines in response to an enhancement of cardiac function. The decrease in adrenergic drive might explain the apparent effect of glucagon in preventing arrhythmias in these patients including those who had paroxysmal arrhythmias in the 24 hour period before glucagon was started.

In this series no improvement was seen in patients with long-standing cardiogenic shock or in patients with chronic congestive heart failure who were maintaining a reasonable blood pressure. Glucagon would appear to be most useful in the treatment of acute hypotension and shock as seen in patients with cardiomyopathies and acute myocardial infarction, and in the low cardiac output state frequently seen following open-heart surgery.

\section{Summary}

A continuous infusion of glucagon in an average dose of $4 \mathrm{mg}$. per hour over several days produced distinct improvement in the clinical state of 12 of 16 patients. Improvement was noted by an increase in blood pressure and urinary output and decrease in dyspnea, pulmonary râles, diaphoresis, and peripheral edema when present. Serum potassium must be carefully monitored. The rise in blood glucose has not been a clinical problem. No cardiac arrhythmias were induced by glucagon, and as cardiac function improved, the heart rate usually decreased. Nausea was the most frequent side effect, but no toxic effects or tachyphylaxis were observed. Long-term therapy with glucagon infusion is both safe and 
highly efficacious in selected patients with severe cardiovascular disease states and is the treatment of choice in cardiac decompensation secondary to beta-blocking agents.

\section{Addendum}

Since this paper was written, Brogan, Kozonis, and Overy (Lancet 1:482, 1969), in consultation with the authors, used the method for continuous glucagon infusion with a successful result in 4 patients.

The authors are grateful to: Drs. Thomas A. Preston and Richard D. Judge for their contribution of case material, to Drs. Herbert E. Sloan and Donald R. Kahn for their cooperation in the study of their patients, and to Dr. F. G. Henderson of Eli Lilly \& Co., Indianapolis, Ind., who kindly supplied the glucagon used in this study.

\section{REFERENCES}

1. Klien, S. W., Morch, J. E., and Mahon, W. A.: Cardiovascular effects of glucagon in man, Canad. Med. Ass. J. 98:1161, 1968.

2. Parmley, W. W., Glick, G., and Sonnenblick, E. H.: Cardiovascular effects of glucagon in man, New Eng. J. Med. 279:11, 1968.

3. Linhart, J. W., Barold, S. S., Cohen, L. S., Hildner, F. J., and Samet, P.: Cardiovascular effects of glucagon in man, Amer. J. Cardiol. 22:706, 1968.

4. Greenberg, B. H., Tsakiris, A. G., Moffit, E. A. and Frye, R. L.: Hemodynamic and metabolic effects of glucagon in patients with valvular heart disease, Amer. J. Cardiol. 23:116, 1969.

5. Elrick, H., Huffman, E. R., Hlad, C. J., Whipple, N., and Straub, A.: Effects of glucagon on renal function in man, J. Clin. Endocr. 18:813, 1958.

6. Schulman, J. L., and Gregen, S. E.: The effect of glucagon on the blood glucose level and the clinical state in the presence of marked insulin hypoglycemia, J. Clin. Invest. 36:74, 1957.

7. Kibler, R. F., and Myers, J. D.: Responsiveness to the pancreatic hyperglycemic glycogenolytic factor (HGF) as a test of liver function, Clin. Res. Proc. $1: 109,1953$.

8. Lawrence, A. M.: Glucagon provocative test for pheochromocytoma, Ann. Intern. Med. 66:1091, 1967.

9. Lucchesi, B. R.: Cardiac action of glucagon, Circ. Res. 22:777, 1968.

10. Glick, G., Parmley, W. W., Wechsler, A. S., and Sonnenblick, E. H.: Glucagon: Its enhancement of cardiac performance in the cat and dog and persistence of its inotropic action despite betareceptor blockade with propranolol, Circ. Res. 22:789, 1968.

11. Whitehouse, F. W., and James, T. N.: Chronotropic action of glucagon on sinus node, Proc. Soc. Exp. Biol. Med. 122:823, 1966. 